\title{
Low-mass secondary-ion ejection from molecular solids by MeV heavy ions: Radial velocity distributions
}

\author{
R. M. Papaléo, * P. Demirev, J. Eriksson, P. Håkansson, and B. U. R. Sundqvist \\ Division of Ion Physics, Department of Radiation Sciences, Uppsala University, Box 535, S-751 21, Uppsala, Sweden
}

(Received 16 January 1996)

\begin{abstract}
Secondary ions sputtered in individual $\mathrm{MeV}$ ion impacts are analyzed in a high resolution time-of-flight mass spectrometer. The initial radial velocity distributions of low mass (up to $\mathrm{m} / \mathrm{z} \approx 300 \mathrm{u}$ ) positive and negative secondary ions, sputtered from carbon-containing molecular solids (polymers, bioorganic molecules, and fullerene targets) are investigated. The first $(\langle v\rangle)$ and second $\left(\left\langle v^{2}\right\rangle\right)$ moments of the velocity distributions vary systematically with the atomic composition of secondary ions of the type $\mathrm{C}_{n} \mathrm{H}_{m}^{+}, \mathrm{C}_{n} \mathrm{~F}_{m}^{+}, \mathrm{C}_{n} \mathrm{H}_{m} \mathrm{~F}^{+}$, and $\mathrm{C}_{n} \mathrm{H}_{m} \mathrm{O}^{+}$. Positive ions formed from extensive fragmentation-rearrangement of the original molecular structure (e.g., $\mathrm{C}_{n}^{+}$) tend to be ejected towards the $\mathrm{MeV}$ ion trajectory (positive mean radial velocity) and to have the largest $\left\langle v^{2}\right\rangle$. Saturated species (e.g., $\mathrm{C}_{n} X_{2 n}, X=\mathrm{F}, \mathrm{H}$ ) tend to have smaller $\left\langle v^{2}\right\rangle$ and negative $\langle v\rangle$. These effects are weaker as the stopping power of the primary ions is decreased and are not observed for negative ions. The observed effects demonstrate a correlation between chemical composition of an ion and its formation and ejection processes. The chemical transformations and the processes leading to ion formation and ejection are functions of both the density and the gradient of the deposited energy at a particular position from the track center. This interconnection results in a regular dependence of the properties of ejected ions (e.g., momentum received) on their chemical composition. The correlation of the momentum imparted to the fragment ions with the geometry of impact indicates that such species are predominantly ejected in a nonevaporative process. [S0163-1829(96)05229-0]
\end{abstract}

\section{INTRODUCTION}

A fast heavy-ion (with velocity much higher than the Bohr velocity, $v_{b}=0.22 \mathrm{~cm} / \mathrm{ns}$ ) penetrating a solid produces a roughly cylindrical region of high electronic energy density (the ion track). ${ }^{1,2}$ This energy can be rapidly converted into atomic motion ${ }^{3}$ and chemical rearrangements, ${ }^{4}$ which may result in ejection of material from the surface and permanent damage to the solid along the ion track. Time-of-flight mass spectrometry has been employed to study such secondary ion emission from solids in individual $\mathrm{MeV}$ ion impact events. ${ }^{5,6}$ Only the nascent (i.e., most energetic) ionic intermediates and reaction products, ejected in a single impact event, are sampled by this technique. However, the ionic component of the electronically sputtered material carries important information about the processes of ion-solid interactions occurring in single $\mathrm{MeV}$ ion tracks on the picosecond time scale. ${ }^{7-12}$ Studies of the material ejected from molecular solids have concentrated on intact large molecular ions, with much less attention to the low mass part of the spectrum composed mostly of fragment ions. Such species, formed after considerable chemical rearrangement-fragmentation, may be suitable probes of the complex chemical events occurring at high-energy densities in ion tracks.

In general, ejection of material from the solid may occur in response to the local energy density at the surface ${ }^{13}$ or in response to the volume force arising from the large radial gradients of the deposited energy. ${ }^{14}$ The velocity distributions of the ejecta can be used to extract information on the operating ejection mechanism. In the case of sputtering due to a volume force (described by pressure pulse ${ }^{14}$ or shock-wave ${ }^{15}$ models), there is a nondiffusive (correlated) momentum transfer from the expanding track core to the ejected molecules. It results in an exit angle correlated with the direction of the incoming projectiles. ${ }^{14}$ This has been clearly observed in the radial velocity distributions of large intact molecular ions (e.g., peptide ions). ${ }^{9,16,17}$ On the other hand, several low-mass ions, originating from, e.g., the fragmentation of such large molecules, showed an initial radial velocity distribution symmetric around the surface normal as expected for ions ejected in an evaporative process. ${ }^{18}$ For instance, Moshammer et al. reported that the fragment ions from valine targets show an angular distribution peaked at the normal, independent of the primary ion angle of incidence. ${ }^{16}$ In contrast, Brinkmalm et al. found later that both $\mathrm{F}^{+}$and carbon cluster ions ejected from poly(vinylidene fluoride) leave the surface preferentially backwards along the direction of the incoming primary ions, in a type of "jet effect." 10 This has indicated that a correlation between the angle of incidence of the projectiles and the exit angle of the ejecta may also occur for fragmented and reconstructed species.

No systematic and accurate characterization of the chemical composition of ejected low-mass ions has been performed in the above studies. Preliminary results of a systematic study performed for a series of low-mass ions ejected from polymeric films, using a high resolution time-of-flight mass spectrometer revealed that the moments of the radial velocity distributions (i.e., the mean velocity and the width) of the positive ions vary in a regular fashion with their chemical composition. $^{11,19}$

Here the nature of this effect is investigated in detail. A systematic study of the radial components of the velocity distributions $\left(v_{x}\right.$ and $\left.v_{y}\right)$ of the molecule-specific and nonspecific positive and negative fragment ions (up to masses 
TABLE I. List of compounds investigated. MW is the average molecular weight.

\begin{tabular}{|c|c|c|}
\hline Compound & Structure & MW (u) \\
\hline Polyethylene $^{\mathrm{a}}$ (PE) & {$\left[-\mathrm{CH}_{2}-\mathrm{CH}_{2}-\right]_{n}$} & 50000 \\
\hline $\begin{array}{l}\text { Poly(tetrafluoroethylene) } \\
\text { (PTFE) }^{\text {b }}\end{array}$ & {$\left[-\mathrm{CF}_{2}-\mathrm{CF}_{2}-\right]_{n}$} & $\approx 10^{6}$ \\
\hline $\begin{array}{l}\text { Poly(vinylidenefluoride) } \\
(\text { PVDF })^{\mathrm{a}}\end{array}$ & {$\left[-\mathrm{CH}_{2}-\mathrm{CF}_{2^{-}}\right]_{n}$} & 534000 \\
\hline Polystyrene $^{c}$ (PS) & {$\left[-\mathrm{CH}_{2}-\mathrm{CH}(\varphi)-\right]_{n}{ }^{\mathrm{a}}$} & 160000 \\
\hline \multicolumn{3}{|l|}{$\begin{array}{l}\text { Polystyrene/ } \mathrm{C}_{60} \\
\left(\mathrm{PS} / \mathrm{C}_{60}\right)\end{array}$} \\
\hline \multicolumn{3}{|l|}{ Nitrocellulose $^{\mathrm{d}}(\mathrm{NC})$} \\
\hline Substance-P $(\mathrm{SP})^{\mathrm{e}}$ & $\mathrm{C}_{63} \mathrm{H}_{98} \mathrm{~N}_{18} \mathrm{O}_{13} \mathrm{~S}$ & 1347.6 \\
\hline Luteinizing hormone & $\mathrm{C}_{55} \mathrm{H}_{75} \mathrm{~N}_{17} \mathrm{O}_{13}$ & 1182.3 \\
\hline \multicolumn{3}{|l|}{$\begin{array}{l}\text { Releasing hormone } \\
(\mathrm{LHRH})^{\mathrm{e}}\end{array}$} \\
\hline Fullerene ${ }^{\mathrm{f}} \mathrm{C}_{60}$ & $\mathrm{C}_{60}$ & 720.6 \\
\hline
\end{tabular}

${ }^{\mathrm{a}}$ Aldrich.

${ }^{\mathrm{b}}$ Goodfellow.

${ }^{\mathrm{c}} \mathrm{BASF}$.

${ }^{\mathrm{d}}$ Bio-Rad.

${ }^{\mathrm{e}}$ Sigma.

${ }^{\mathrm{f}}$ MER Corporation.

${ }^{\mathrm{g}} \varphi$ denotes the phenyl ring $\left(\mathrm{C}_{6} \mathrm{H}_{5}\right)$.

around $300 \mathrm{u}$ ) sputtered from polymers, bioorganic molecules, and fullerene targets are reported. The interconnection between secondary ion chemical composition and the velocity distributions of such ions is found to be a general feature in the electronic sputtering of organic solids. We argue that this correlation between the ejection dynamics and the ion chemical composition reflects the fast-ion track structure and the geometry of impact. That is, it results from the spatial inhomogeneity of the energy deposition events in the track and the existence of different locations where particular ions are formed relative to the point of impact.

\section{EXPERIMENT}

\section{A. Target preparation}

Compounds with predominantly carbon backbone have been investigated and are given in Table I. The targets in the different experiments were deposited on $1 \times 1 \mathrm{~cm}^{2} \mathrm{Si}$ substrates, except for poly(tetrafluorethylene) (PTFE) targets, which were self-supported 5 - $\mu$ m-thick foils covered with a thin $\mathrm{Au}$ layer. In this case stainless-steel disks were used as backing material. The blend of polystyrene and $\mathrm{C}_{60}\left(\mathrm{PS} / \mathrm{C}_{60}\right)$ (10:1 by weight) was prepared by codissolution in toluene. Poly(vinylidene fluoride) (PVDF), nitrocellulose (NC), polystyrene (PS) and $\mathrm{PS} / \mathrm{C}_{60}$ films were prepared by spin coating, using a $10-\mathrm{mg} / \mathrm{ml}$ solution in acetone (for PVDF and NC) or toluene (for PS and $\mathrm{PS} / \mathrm{C}_{60}$ ). Polyethylene (PE) films were prepared by dipping Si backings in a $10-\mathrm{mg} / \mathrm{ml}$ solution in toluene at $80{ }^{\circ} \mathrm{C}$. $\mathrm{C}_{60}$ thin films were prepared by vacuum sublimation (at $\approx 10^{-6}$ torr) onto $\mathrm{Si}$ substrates. The peptides luteinizing hormone releasing hormone (LHRH) and substance-P (SP) were dissolved in a mixture of $80 \%$ acetic acid and $20 \%$ trifluoracetic acid at a concentration of 10 $\mathrm{mg} / \mathrm{ml}$. LHRH and SP films were prepared by electrospray- ing the solution onto $\mathrm{Si}$ substrates. The target thicknesses were monitored by ellipsometry or atomic force microscopy (AFM). The prepared thin films had thicknesses around 5-500 nm. The electrosprayed peptide films were somewhat thicker (on the order of $\mu \mathrm{m}$ ).

AFM images showed an irregular topography of the PVDF films on a micrometer scale. This is probably due to the tendency of the chains to crystallize from the solution during the spinning. For that reason, ellipsometry measurements on these films provide only the average thickness. PS and $\mathrm{PS} / \mathrm{C}_{60}$ films were flatter. The mean roughness for PS in a $2 \times 2 \mu \mathrm{m}^{2}$ scan was typically $0.15 \mathrm{~nm}$, with features with maximum height of $1.5 \mathrm{~nm}$. For PVDF films these values were around 10 and $100 \mathrm{~nm}$, respectively. Sublimated $\mathrm{C}_{60}$ films were polycrystalline (grains typically with $150-200 \mathrm{~nm}$ diameter) with an average roughness around $10 \mathrm{~nm}$. Electrosprayed targets presented the most irregular surfaces (mean roughness about $60 \mathrm{~nm}$, in a $5 \times 5 \mu \mathrm{m}^{2}$ scan), giving grainy deposits of micrometer dimensions. ${ }^{20}$ Morphology analyses were not performed for PTFE, NC, and SP.

\section{B. Instrumental setup}

$\mathrm{MeV}$ atomic ions from the Uppsala EN-tandem accelerator, incident on the targets at an angle of $45^{\circ}$ and at a rate of $2000-4000 \mathrm{~s}^{-1}$ were used as projectiles. In most of the radial velocity measurements $72.3 \mathrm{MeV}{ }^{127} \mathrm{I}^{13+}$ ions were used as primary ions. In the experiments on the radial velocity distribution dependence on the $\mathrm{MeV}$ ion stopping power, the targets were irradiated with $0.61 \mathrm{MeV} / \mathrm{amu}$ (around five times the Bohr velocity) ${ }^{16} \mathrm{O}^{3+},{ }^{32} \mathrm{~S}^{3+},{ }^{79} \mathrm{Br}^{9+}$, and ${ }^{127} \mathrm{I}^{14+}$ ions. A reflectron time-of-flight (TOF) mass spectrometer ${ }^{21}$ was used for secondary ion analysis. Before reaching the target, the primary ions passed through a thin carbon foil, inducing secondary electron emission to give the start signal for the timing electronics. Therefore, they were in charge state equilibrium when impacting the targets. The area on the target impacted by the beam was defined by a $1 \times 1 \mathrm{~mm}^{2}$ slit and a 1.2-mm-diam collimator placed before and after the carbon foil, respectively. The positive (negative) secondary ions were accelerated by a potential $V_{a}$ of $+(-) 14.00 \mathrm{kV}$, traversing a field-free flight tube before reaching a singlestage electrostatic ion mirror at a potential $V_{r}=+(-) 15.66$ $\mathrm{kV}$. The electrostatic ion mirror corrects for the dispersion in the initial axial velocity of the ejected species, improving the mass resolution. ${ }^{21}$ The ion flight time registration was performed by a time-to-digital converter (IPN, Orsay, France) with $0.5-n s$ time resolution. Typically $4 \times 10^{6}$ primary ion impacts were accumulated for each mass spectrum. A scheme of the TOF spectrometer is displayed in Fig. 1.

The initial radial (tangential) velocity distributions were obtained by monitoring the secondary ion yields as a function of the voltage applied to two sets of deflection plates (in the $x$ or $y$ direction perpendicular to the target surface normal). The plates were installed parallel to the ion optical axis of the TOF mass spectrometer. To determine $v_{x}\left(v_{y}\right)$, the yield of low-mass ions was maximized by setting the appropriate potential on the $y(x)$ deflection plates, and then data were acquired for different voltages $V_{d x}\left(V_{d y}\right)$ applied to the $x(y)$ deflection plates. The procedure for measurement of the initial radial velocity distribution has been described in more detail elsewhere. ${ }^{10,18}$ 
Conversion from voltage units to velocity units was performed according to ${ }^{10,18}$

$$
v_{i}=k_{i} \frac{q}{|q|} \frac{V_{0 i}-V_{d i}}{\sqrt{m}}
$$

The index $i$ refers to the $x$ or $y$ components, $m$ and $q$ are the ion mass and charge, $k_{i}$ is a constant depending on $V_{a}, V_{r}$ and on the geometrical parameters of the instrument,

$$
k_{i}=\left(\frac{|q|}{2 V_{a}}\right)^{1 / 2} \frac{\left(l_{d z}+\Delta l_{d z}\right)}{l_{d x}} \frac{\left[(1 / 2) l_{d z}+l_{3}+4 l_{4}\left(V_{a} / V_{r}\right)+l_{6}+(2 / \alpha) l_{7}+\beta\left(l_{2}+l_{d z}\right)\right]}{\left[2 l_{0}+l_{1}+l_{2}+2 l_{d z}+l_{3}+4 l_{4}\left(V_{a} / V_{r}\right)+l_{6}+(2 / \alpha) l_{7}\right]},
$$

with

$$
\alpha=1+\left[1-\frac{q}{|q|} \frac{V_{p}}{V_{a}}\right]^{1 / 2} \text { and } \beta= \begin{cases}0 & \text { for } k_{x}, \\ 1 & \text { for } k_{y} .\end{cases}
$$

$V_{p}$ is the voltage applied to the first stop detector channel plates $\left(V_{p}=-2.6 \mathrm{kV}\right)$ and $\Delta l_{d z}$ is the first-order correction to the length of the finite deflection plates. ${ }^{18}$ For the definitions of the distances see the caption of Fig. $1 . V_{0 i}$ in Eq. (1) is the voltage on the deflection plates required for an ion with a zero $i$-velocity component to reach the center of the stop detector. For perfect alignment of the spectrometer optical axis with the beam spot position and the normal to the sample surface, $V_{0 i}=0$. This condition is very difficult to achieve and the centroid of the velocity distribution of $\mathrm{C}_{2} \mathrm{H}_{3}^{+}$ ions, ejected approximately normal to the target surface ${ }^{18}$ was used for estimating $V_{0 i}$. For the negative ions, $V_{0 i}$ was determined from the centroid of the $\mathrm{C}_{2} \mathrm{H}_{2}^{-}$velocity distribution. The velocity distributions were obtained by fitting a Gaussian curve to the experimental data. The mean radial velocities $\left\langle v_{x}\right\rangle$, and the mean-square velocities, $\left\langle v_{x}^{2}\right\rangle$, or the width of the distributions were calculated using Eq. (1) and averaging over the velocity distributions for each ion. Throughout the paper we have used the term "radial velocity" for brevity, although its $x(y)$ component, $v_{x}\left(v_{y}\right)$ Fig. 1 , were actually measured and reported. The signs of the velocities are defined by the coordinate system in Fig. 1. An ion with positive $x$ and $z$ velocities is ejected back along the line of incidence of the $\mathrm{MeV}$ primary ions.

\section{Effect of the stop detector collimator}

The diameter of the collimator placed in front of the stop detector (Fig. 1) is the most important instrumental parameter defining the range of velocities within which ions are collected for a particular voltage applied to the deflection plates. The effect of the collimator aperture on the radial velocity was examined by collecting the velocity distributions of secondary ions from $\mathrm{CsBr}$ and PVDF targets at three different apertures: 4.8, 20, and $35 \mathrm{~mm}$. Several ions were investigated and the result for $(\mathrm{CsBr}) \mathrm{Br}^{+}$(from a $\mathrm{CsBr}$ target) is shown in Fig. 2. The widths of the distributions were typically $10-20 \%$ smaller using a $4.8-\mathrm{mm}$ aperture compared to the distribution taken with a $35-\mathrm{mm}$ stop detector opening, despite the broad range of velocities accepted in each experimental point in the last case. No systematic influence on the centroids of the distributions were detected. As the effect of the aperture on the velocity distributions is weak and the stop rate decreases considerably for a small aperture, a value of $19 \mathrm{~mm}$ has been chosen as standard.

Other instrumental effects such as divergency due to the acceleration grids ${ }^{22}$ and finite size of the irradiated spot on

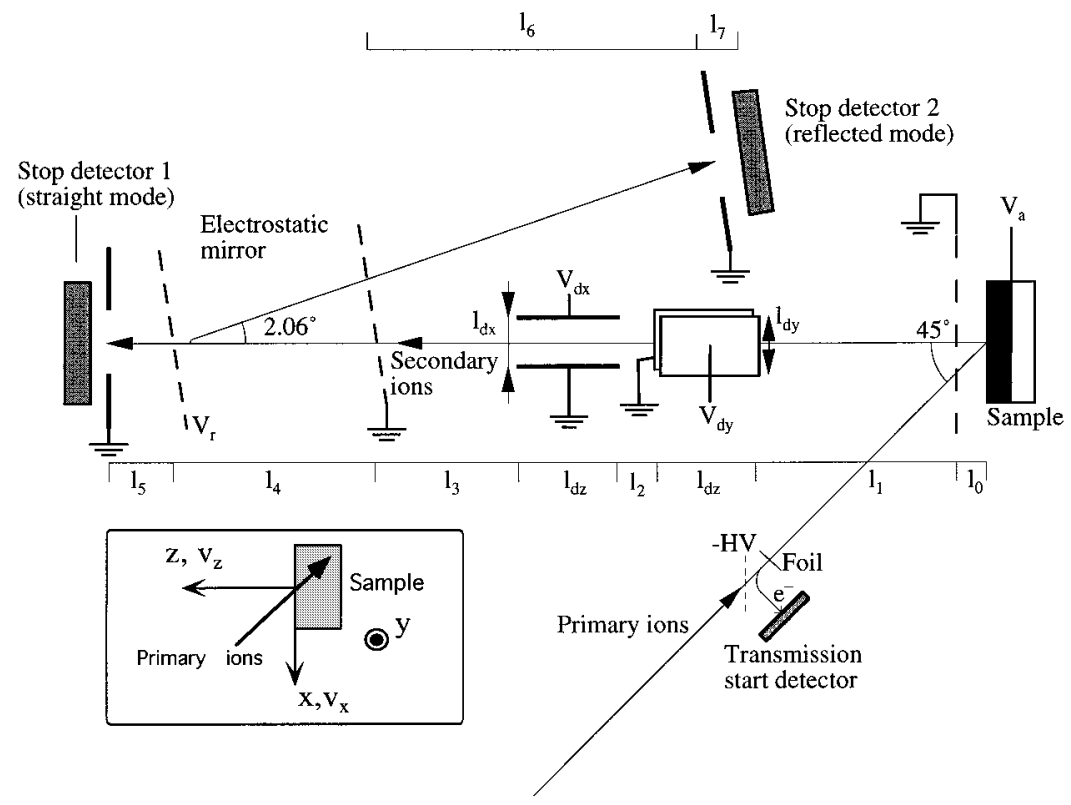

FIG. 1. Schematic diagram of the time-offlight mass spectrometer. The actual lengths are $l_{0}=4.5 \mathrm{~mm} ; l_{1}=130 \mathrm{~mm} ; l_{d z}=25 \mathrm{~mm} ; l_{2}=11$ $\mathrm{mm} ; l_{d y}=16 \mathrm{~mm} ; l_{3}=494 \mathrm{~mm} ; l_{4}=289 \mathrm{~mm}$; $l_{6}=435 \mathrm{~mm} ; l_{7}=10 \mathrm{~mm}$. The separation between both pairs of plates (in the $x$ and $y$ direction) is $l_{d x}=14 \mathrm{~mm}$. The inset shows the coordinate system. An ion with positive $v_{x}$ and $v_{z}$ is ejected backwards along the line of incidence of the $\mathrm{MeV}$ primary ions. 


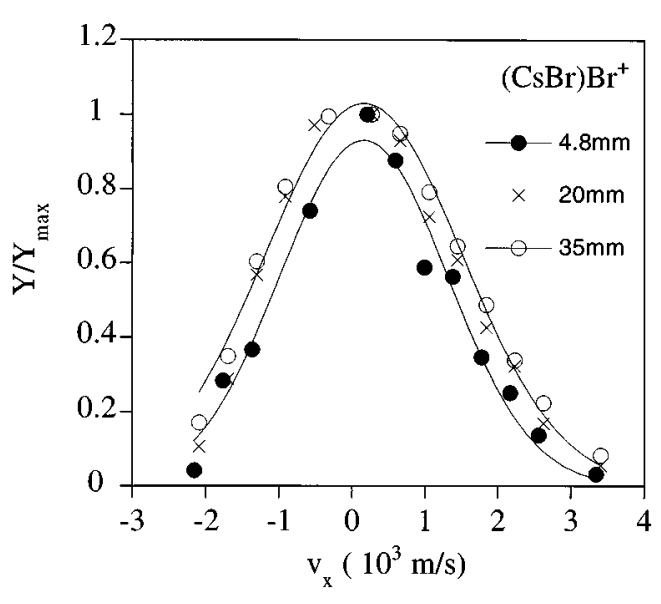

FIG. 2. Radial velocity distribution ( $v_{x}$ component $)$ of $(\mathrm{CsBr}) \mathrm{Br}^{+}$ejected from a $\mathrm{CsBr}$ target using $72.3-\mathrm{MeV}{ }^{127} \mathrm{I}^{+13}$ as primary ions. The velocity distributions were acquired at three different apertures of the iris in front of the stop detector: 4.8, 20, and $35 \mathrm{~mm}$. $Y_{\max }$ is the maximum value of the yield in each distribution.

the targets can, as well, introduce a broadening in the velocity distribution. A rough estimate of all such contributions (including detector aperture) is about $50 \%$ of the measured width. The final shape of the distributions may also be affected by scattering due to collisions in the gas phase and the velocity spread arising from ejection of a species from different locations in the track (e.g., from fragmentation of colder, larger precursors and fragmentation in the highenergy density zone, see below).

\section{RESULTS}

\section{A. Mass resolution and chemical composition assignment}

In this paper a correlation between the chemical composition of the various secondary ions and their respective velocity distributions is established. A prerequisite for this is an unambiguous determination of the chemical composition of each ion in the mass spectrum. While for PE and PS this is relatively straightforward, the presence of different types of heteroatoms, mainly for the peptide and PVDF targets, gives rise to doublet or triplet peaks corresponding to isobar ions. The reflectron TOF spectrometer employed here ${ }^{21}$ has an average resolution, $m / \delta m \approx 5000$. In the mass region up to 100 $\mathrm{u}$, peaks corresponding to ions with masses that differ by $\approx 0.02 \mathrm{u}$ can be resolved, while the average mass accuracy for singlet peaks is typically $0.004 \mathrm{u}$. However, it has been observed for all investigated polymers that hydrocarbon ions with a larger number of hydrogens in each of the various $\mathrm{C}_{n} \mathrm{H}_{m}$ series tend to have systematically longer flight times than expected (i.e., they appear "heavier"'). The effect seems not to be related to a possible spread in the initial axial velocity of the secondary ions as the electrostatic mirror should compensate for it. This systematic "mass defect" is tentatively attributed to an initial time spread ("time lag") during ion formation. ${ }^{23}$ Therefore, the time-to-mass calibration has been performed using intense ion peaks with well established chemical composition and containing a varying number of
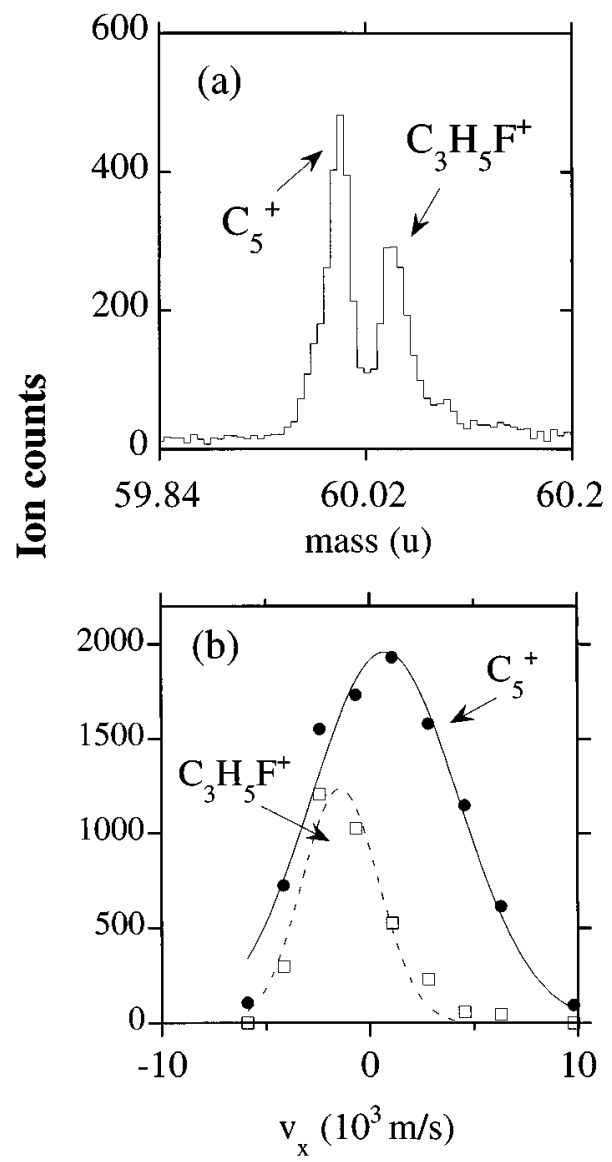

FIG. 3. (a) Doublet $\left(\mathrm{C}_{3}^{+}, 59.999 \mathrm{u}\right.$ and $\left.\mathrm{C}_{3} \mathrm{H}_{5} \mathrm{~F}^{+}, 60.037 \mathrm{u}\right)$ around $m=60 \mathrm{u}$ in the positive ion mass spectrum of a PVDF target. (b) Radial velocity distributions ( $x$ component) of the same secondary ions. Primary ions: $72.3-\mathrm{MeV}^{127} \mathrm{I}^{13+}$.

hydrogen atoms (e.g., $\mathrm{H}^{+}, \mathrm{C}^{+}, \mathrm{C}_{2} \mathrm{H}_{3}^{+}, \mathrm{C}_{3} \mathrm{H}_{5}^{+}$). This procedure gives more accurate masses, as differences in the time of flight due to initial time spread during ion formation are averaged. Even after applying such a procedure, a systematically larger mass deviation, $\Delta m$ (the difference between the measured ion mass and the expected mass calculated from its proposed chemical composition) has been observed for the peptide immonium ions. These are fingerprint ions characteristic of the peptide's constituent aminoacids. The assignment in this case is inferred from their higher intensity and from the aminoacid sequence of the investigated peptides, which are well known. In the mass spectra of LHRH, SP, and NC targets, ions of the type $\mathrm{C}_{n} \mathrm{H}_{m}^{+}$are clearly distinguished. The major problem in the chemical composition assignment has been the differentiation of structures of the type $\mathrm{C}_{n} \mathrm{H}_{m} \mathrm{~N}_{p}$ from $\mathrm{C}_{n} \mathrm{H}_{m-2} \mathrm{O}_{p}$ which in some cases was not possible. For PE, PS, and PVDF, ions of the type $\mathrm{C}_{n} \mathrm{H}_{m}^{+}$(and $\mathrm{C}_{n} \mathrm{H}_{m} \mathrm{~F}^{+}$for PVDF) dominate the low-mass region. In the case of PTFE, $\mathrm{C}_{n} \mathrm{~F}_{m}^{+}$ions dominate the whole spectrum. Details of the procedure for chemical composition assignment for PVDF, PS, and PTFE have been described elsewhere. ${ }^{11,19}$

The yield (area) of each component of a multiplet was deconvoluted by fitting multiple Gaussians to the whole group of peaks. An example for a doublet is given in Fig. 3 for $\mathrm{C}_{3}^{+}$and $\mathrm{C}_{3} \mathrm{H}_{5} \mathrm{~F}^{+}$ions (both with $m / z \approx 60$ ) ejected from PVDF targets. The mean velocity and width of the velocity 


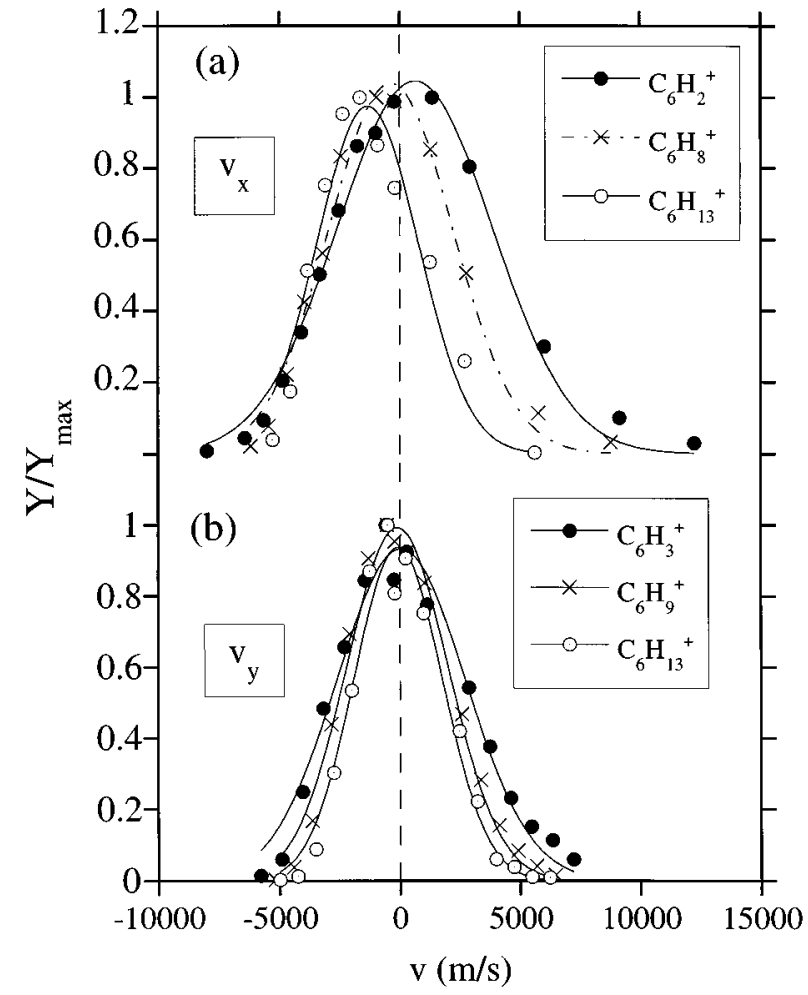

FIG. 4. The $v_{x}$ (a) and $v_{y}$ (b) component of the radial velocity distributions of $\mathrm{C}_{6} \mathrm{H}_{m}^{+}$ions ejected from $\mathrm{PE}$ films by $72.3-\mathrm{MeV}$ ${ }^{127} \mathrm{I}^{13+}$ ions. $Y_{\max }$ is the maximum value of the yield in each distribution.

distributions for these two ions are quite different: e.g., $\left\langle v_{x}\right\rangle$ is $770 \pm 260 \mathrm{~m} / \mathrm{s}$ for $\mathrm{C}_{5}^{+}$and $-1400 \pm 240 \mathrm{~m} / \mathrm{s}$ for $\mathrm{C}_{3} \mathrm{H}_{5} \mathrm{~F}^{+}$. The averaged $\left\langle v_{x}\right\rangle$ is close to zero without the deconvolution. This finding exemplifies the type of correlation between the velocity distributions and chemical composition observed for a very large number of secondary ions, which is described in detail below.

\section{B. $v_{x}$-velocity distributions for $\mathrm{C}_{n} \mathrm{H}_{m}^{+}$and $\mathrm{C}_{n} \mathrm{H}_{m}^{-}$ion series}

A plot of the $v_{x}$-velocity distributions of $\mathrm{C}_{6} \mathrm{H}_{m}^{+}$ ions ejected from a PE target is shown in Fig. 4(a). The differential yields are normalized to the maximum value in each distribution. The centroids of the velocity distributions, $\left\langle v_{x}\right\rangle$, change from a positive value for $\mathrm{C}_{6} \mathrm{H}_{2}^{+}$to a negative $\left\langle v_{x}\right\rangle$ for $\mathrm{C}_{6} \mathrm{H}_{13}^{+}$. At the same time, the larger the number of hydrogen atoms in the $\mathrm{C}_{6} \mathrm{H}_{m}^{+}$ions, the narrower is the width of the distributions. The $\left\langle v_{x}\right\rangle$ and the FWHM $\left[=(1 / 2) m\left\langle v_{x}^{2}\right\rangle-(1 / 2) m\left\langle v_{x}\right\rangle^{2}\right.$, or simply $\left\langle v_{x}^{2}\right\rangle$, for brevity] obtained from the velocity distributions of all the $\mathrm{C}_{n} \mathrm{H}_{m}^{+}$series analyzed (up to $m / z=120$ ) is given in Fig. 5 as a function of ion mass. Both $\left\langle v_{x}\right\rangle$ and $\left\langle v_{x}^{2}\right\rangle$ vary regularly with ion mass with 12 (one C atom) as a "repeat unit." No correlation between ion yield intensities and the values of $\left\langle v_{x}\right\rangle$ and FWHM are detected.

Secondary ions with no hydrogen or low hydrogen content have mean velocities with positive sign (ejected away from the surface normal, and towards the primary ion trajectory, see Fig. 1 for the coordinate system). This is similar to the ejection of $\mathrm{C}_{60}$ ions from PVDF. ${ }^{10}$ The values of $\left\langle v_{x}\right\rangle$

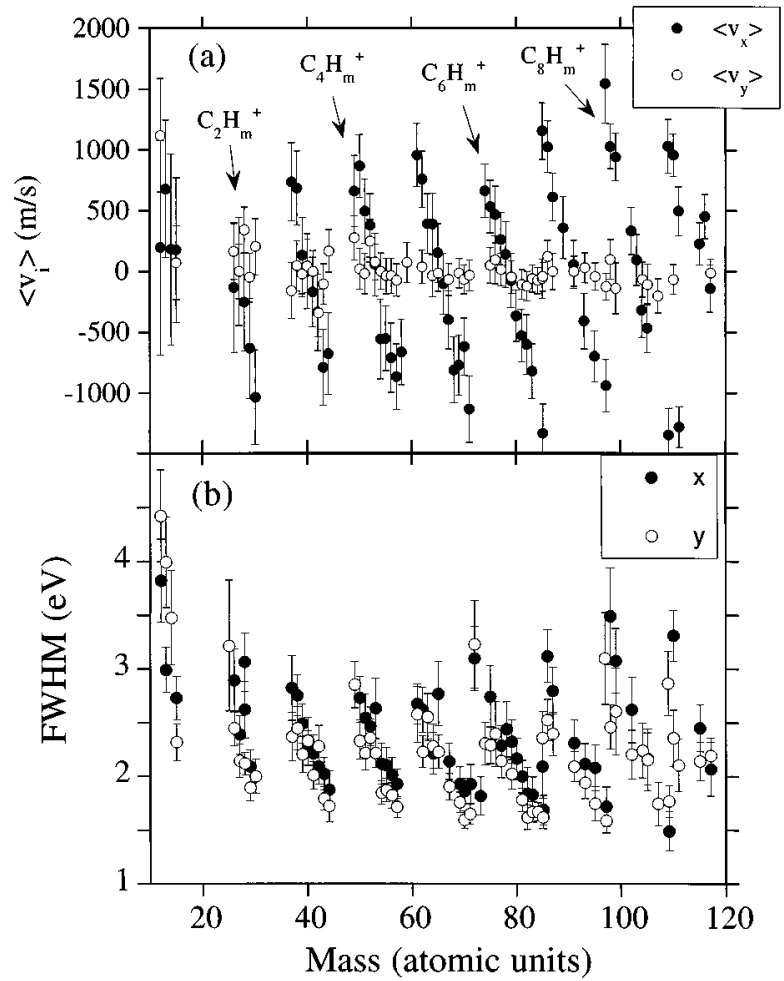

FIG. 5. (a) Mean velocities $\left\langle v_{i}\right\rangle$ and (b) FWHM $\left.\left(=0.5 m\left[\left\langle v_{x}^{2}\right\rangle-\left\langle v_{x}\right\rangle^{2}\right\rangle\right]\right)$ of the $x$ and $y$ velocity distributions of hydrocarbon secondary ions ejected from PE films as a function of ion mass. Primary ions: $72.3-\mathrm{MeV}^{127} \mathrm{I}^{13+}$.

decrease for ions with higher hydrogen content, eventually reaching negative mean velocities for ions with the highest number of hydrogen atoms in each $\mathrm{C}_{n} \mathrm{H}_{m}^{+}$series. These ions are ejected again off the surface normal, but away from the incident ion trajectory. The effect is similar to the one observed for intact biomolecular ions. ${ }^{9,16-18,24}$ This indicates that a nonrandom momentum transfer is also involved in the sputtering of the low-mass species. If evaporative-type processes were dominant, $\left\langle v_{x}\right\rangle \approx 0$ would be expected. In a similar fashion, ions with a higher degree of hydrogenation tend to have lower mean radial kinetic energies and vice versa [Fig. 5(b)]. There is a clear correlation between FWHM and chemical composition similar to what is observed for the $\left\langle v_{x}\right\rangle$.

Such behavior has been seen for the $\left\langle v_{x}\right\rangle$ of $\mathrm{C}_{n} \mathrm{H}_{m}^{+}$ejected from all polymers, ${ }^{11,19}$ peptides, and $\mathrm{PS} / \mathrm{C}_{60}$ targets. A summary of the collected data for the different targets is given in Table II. In the case of PS it is possible to extend the analyzed mass range for the hydrocarbon ions up to $200 \mathrm{u}$. The results for $\left\langle v_{x}\right\rangle$ are shown in Fig. 6. Although the variation of the $\left\langle v_{x}\right\rangle$ values is somewhat smaller compared to the lighter ions (not shown here ${ }^{11}$ ) the correlation between the degree of hydrogenation and $\left\langle v_{x}\right\rangle$ is still clearly seen. Examples are given by the doublet peaks corresponding to $\mathrm{C}_{n} \mathrm{H}_{m}^{+}$and $\mathrm{C}_{n-1} \mathrm{H}_{m+12}^{+}$ions (e.g., at 144, 168, $182 \mathrm{u}$ ). Interestingly, a similar correlation between degree of fluorination and the radial velocity distributions has been observed for $\mathrm{C}_{n} \mathrm{~F}_{m}^{+}$ejected from PTFE films. ${ }^{19}$ This finding indicates that the dependence of the moments of the velocity distribution on the chemical composition of the secondary ions is not 
TABLE II. Summary of the results obtained for the velocity distributions of hydrocarbon $\left(\mathrm{C}_{n} \mathrm{H}_{m}\right)$ positive ions ejected from different organic films. "Periodicity" here means the observation of systematic variations in the mean velocity $\left\langle v_{i}\right\rangle$ or FWHM values with the degree of hydrogenation of the secondary ions. The $\left\langle v_{x}\right\rangle$ and FWHM ranges give the maximum and minimum values obtained for these quantities for each target. For all targets the "zero" of the velocity scale is defined by the mean velocity of $\mathrm{C}_{2} \mathrm{H}_{3}^{+}$.

\begin{tabular}{|c|c|c|c|c|c|c|}
\hline Target & $\begin{array}{l}\left\langle v_{x}\right\rangle \\
\text { periodicity }\end{array}$ & $\begin{array}{c}\left\langle v_{x}\right\rangle \text { range } \\
\left(10^{3} \mathrm{~m} / \mathrm{s}\right)\end{array}$ & $\begin{array}{l}\text { FWHM } \\
\text { periodicity }\end{array}$ & $\begin{array}{c}\mathrm{FWHM}^{\mathrm{a}} \\
\text { range }(\mathrm{eV})\end{array}$ & $\begin{array}{l}\left\langle v_{y}\right\rangle \\
\text { periodicity }\end{array}$ & Thickness \\
\hline PE & Yes & $-1.5-1.2$ & Yes & $2.7-7.0$ & & $>1 \mu \mathrm{m}$ \\
\hline PE & Yes & $-1.5-1.2$ & Yes & $1.5-4.5$ & No & $<1 \mu \mathrm{m}$ \\
\hline PVDF & Yes & $-1.0-1.0$ & Yes & $1.5-4.5$ & No & $100 \mathrm{~nm}$ \\
\hline PTFE & Yes & $-1.0-1.2$ & Yes & $2.0-7.0$ & & $5 \mu \mathrm{m}$ \\
\hline PS & Yes & $-0.5-0.7$ & Partial $^{\mathrm{b}}$ & $1.5-4.0$ & No & $100 \mathrm{~nm}$ \\
\hline $\mathrm{PS} / \mathrm{C}_{60}$ & Yes & $-0.5-1.0$ & Yes & $1.5-4.0$ & & $100 \mathrm{~nm}$ \\
\hline LHRH & Yes & $-1.7-1.8$ & Yes & $4.0-13.0$ & & $>2 \mu \mathrm{m}$ \\
\hline $\mathrm{NC}$ & Yes & $-0.5-0.5$ & Yes & $1.2-3.2$ & & $6 \mathrm{~nm}$ \\
\hline $\mathrm{NC}$ & Yes & $-0.8-0.9$ & Yes & $2.4-4.0$ & & $45 \mathrm{~nm}$ \\
\hline SP & Yes & $-0.6-1.4$ & Yes & $1.8-3.0$ & & \\
\hline $\mathrm{C}_{60}$ & No & $\cdots$ & Yes & $1.0-2.5$ & & $100 \mathrm{~nm}$ \\
\hline
\end{tabular}

${ }^{\mathrm{a}}$ Data from the $v_{x}$ distributions.

${ }^{\text {b}}$ Values for the $\mathrm{C}_{n} \mathrm{H}_{m}(n=1,2)$ series. For higher $n$ the periodic behavior is not clearly demonstrated.

coupled to a specific property of hydrocarbon ions. It gives additional evidence for the connection between the observed "chemical" effect and the ion track momentum and energy density radial profiles, as discussed below.

Even though electronic sputtering is a fast nonequilibrium process, it is reasonable to assume that the local energy density (or "temperature") at the time and place of emission, $e(r, t)$, is proportional to the width of the velocity distributions. ${ }^{7,25-28}$ It is expected that a complete destruction of the original molecular structure together with the preferential elimination (by diffusion and/or ejection) of $\mathrm{H}, \mathrm{O}$, and $\mathrm{F}$ atoms, occurs in the innermost parts of the track where the energy density is highest. Pure carbon clusters $\mathrm{C}_{n}^{+}$, which have the broadest velocity distributions should originate preferentially from this "hot" region. At the outer zones of the track, the survival probability for hydrogenated frag-

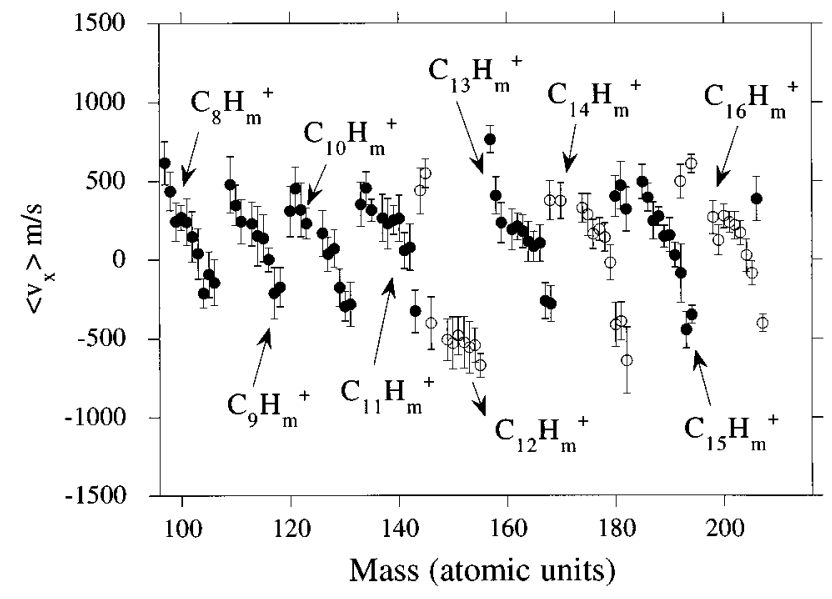

FIG. 6. Mean velocities $\left\langle v_{x}\right\rangle$ of hydrocarbon secondary ions $\left(\mathrm{C}_{n} \mathrm{H}_{m}^{+}, 8 \leqslant n \leqslant 16\right)$ ejected from a PS film bombarded with 72.3$\mathrm{MeV}^{127} \mathrm{I}^{13+}$, as a function of ion mass. For clarity, the results from the $\mathrm{C}_{12} \mathrm{H}_{\mathrm{m}}^{+}, \mathrm{C}_{14} \mathrm{H}_{m}^{+}$, and $\mathrm{C}_{16} \mathrm{H}_{\mathrm{m}}^{+}$hydrocarbon series are shown as open circles. ments increases, and heteroatom depletion is not strong, thus enhancing the probability of recombination reactions involving, e.g., $\mathrm{H}, \mathrm{F}$, and $\mathrm{C}$ atoms. The lower mean kinetic energies (FWHM) of ions with increasing number of hydrogen atoms are an indication that they are formed further away from the track core where the energy density is lower. In short, the decrease in the width (mean kinetic energy) of the velocity distributions as the hydrogen content increases reflects the radial profile of the deposited energy density in the heavyion track. Therefore, it is plausible to infer that the chemical effect observed is actually an expression of the different loci (and/or time) of ion production relative to the point of the $\mathrm{MeV}$ ion impact. This overall picture of fragmented ions originating from the inner parts of the track, in contrast to more intact species emitted from the outer zones, has been suggested by several authors. ${ }^{18,24,29-31}$ The important contribution here is that a detailed mapping of the radial effects around the ion track is experimentally demonstrated.

A smooth variation of the momentum imparted to the ejecta with the radial distance from the track would explain qualitatively the observed transition from positive (axial direction) to negative (radial direction) mean velocities as the number of hydrogen atoms increases in each $\mathrm{C}_{n} \mathrm{H}_{m}$ series. Both the pressure pulse and shock-wave models ${ }^{14,32,33}$ predict a dependence of the momentum imparted to the ejecta on the position of ion emission. [This is also expected from direct electrostatic interactions between emitted ions and the positive charges trapped in the track, if the neutralization is slow compared to the average time of ejection (and if the track cylindrical geometry is maintained during ejection)]. Moreover in these models, material ejected from radial distances $r>R_{i}$, the initial track width, ${ }^{14}$ is expected to acquire negative $\left\langle v_{x}\right\rangle$ values (in our geometry). Ejecta from the core $\left(r<R_{i}\right)$ would receive an impulse predominantly back along the track, acquiring a positive $\left\langle v_{x}\right\rangle .{ }^{14}$ Based on this picture of the ejection process, the observed dependence of the mean radial velocities can be again interpreted to be a consequence of the different loci of ion production and ejection relative to the point of impact. 
In contrast to the positive ions, the negative $\mathrm{C}_{n} \mathrm{H}_{m}^{-}$have $\left\langle v_{x}\right\rangle$ and $\left\langle v_{x}^{2}\right\rangle$ which are roughly constant as a function of ion mass. ${ }^{11}$ Only $\mathrm{H}^{-}$shows a clearly different $\left\langle v_{x}\right\rangle$ from the majority of the other ions in the mass range up to $200 \mathrm{u}$. The relatively lower values and the lack of dependence of both $\left\langle v_{x}\right\rangle$ and $\left\langle v_{x}^{2}\right\rangle$ on the ion type suggests that these ions are ejected at later times, after the track neutralized, and "cooled" considerably or preferentially from regions far from the track core. It also suggests that evaporative ejection dominates for these ions. We note that the number of hydrogens in the $\mathrm{C}_{n} \mathrm{H}_{m}^{-}$series is small $(m \leqslant 3)$. This may effectively limit the observation of a chemical composition effect typical for the positive ions.

It should be noted that the behavior of the $\left\langle v_{x}^{2}\right\rangle$ varies for various targets (Table II). The connection of the width of the distributions to the chemical composition of the secondary ions is clearly expressed for PVDF, PE, and PTFE targets. However, in PS it is only seen for the $\mathrm{CH}_{m}^{+}$and $\mathrm{C}_{2} \mathrm{H}_{m}^{+}$series. For higher masses that effect is smeared out. ${ }^{11} \mathrm{~A}$ weak dependence of the $\left\langle v_{x}^{2}\right\rangle$ on the hydrogen content can be discerned in some of the higher $\mathrm{C}_{n} \mathrm{H}_{m}^{+}$series (e.g., $\mathrm{C}_{5} \mathrm{H}_{m}^{+}$and $\mathrm{C}_{7} \mathrm{H}_{m}^{+}$), but the small variations are on the order of our experimental uncertainties. As the primary ions deposit roughly the same amount of energy in all tested materials, sampledependent factors may also contribute to the width of the velocity distributions. One possibility is the specific radiation chemistry induced in each target. The energy released in the breaking and/or formation of new chemical bonds in the ion track may add to the energy deposited directly by the primary ions, or it may influence the ion-track lifetime. The lower values of $\left\langle v_{x}^{2}\right\rangle$ for secondary ions from PS is probably indicative of a lower local temperature (energy density) or a faster quenching of the deposited energy. The sample thickness and roughness may influence the width of the velocity distributions as well, as already pointed out. ${ }^{12,27,34,35}$ The thickness effect is specifically discussed in Sec. III E.

\section{C. $v_{y}$-velocity distributions for $\mathrm{C}_{n} \mathrm{H}_{m}^{+}$ions}

The $v_{y}$-velocity distributions of $\mathrm{C}_{6} \mathrm{H}_{m}^{+}$ions ejected from a PE target are shown in Fig. 4(b), and the mean velocities and width of the distributions of the various hydrocarbon ion series in Fig. 5. The $\left\langle v_{y}^{2}\right\rangle$ vary systematically with ejected ion mass, showing a similar correlation with the degree of hydrogenation as discussed above for the $v_{x}$ distributions. However, contrary to the $v_{x}$ distributions, the $v_{y}$ distributions are centered around $v_{y}=0$, independent of the chemical composition of the secondary ions [Fig. 4(b) and Fig. 5(a)]. This behavior is actually expected, and follows from the arguments presented in the discussion of the $v_{x}$ data (Sec. III B), taking into account the symmetry of the $\mathrm{MeV}$ ion in impact. The trajectory of the incident $\mathrm{MeV}$ ions lies in the $x z$ plane and, as the angle of incidence is $45^{\circ}$, preferential directions for energy deposition and propagation not coinciding with the surface normal are introduced. The axial and the radial expansion of the track define two different projections of the ejection "vectors" on the $x z$ plane (ejection due to radial expansion gives negative $\left\langle v_{x}\right\rangle$, and ejection due to the axial expansion gives positive $\left.\left\langle v_{x}\right\rangle\right)$. This gives rise to the systematic pattern in Fig. 5 for the $\left\langle v_{x}\right\rangle$, as discussed in the previous section. In turn, the $y$ axis is a symmetry axis (since $\mathrm{MeV}$ ion trajectories lie in the $x z$ plane) and ejection pro-
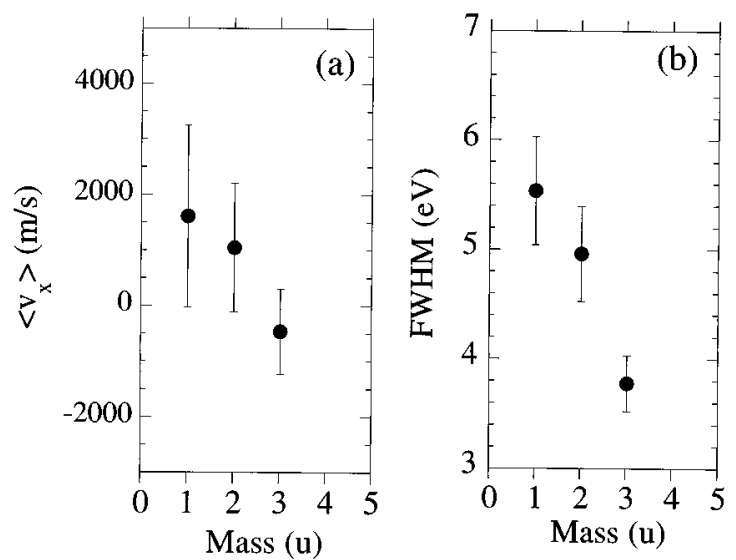

FIG. 7. (a) Mean radial velocity $\left(v_{x}\right.$ component) and (b) FWHM of $\mathrm{H}_{n}^{+} \quad(n=1,2,3)$ ejected from NC films impacted by $72.3-\mathrm{MeV}$ ${ }^{127} \mathrm{I}^{13+}$ ions.

duced by either radial or axial "push," as well as any evaporative ejection would give $v_{y}$ distributions which are symmetric in the $y z$ plane. ${ }^{33}$

\section{Specific cases}

Secondary ions different from the hydrocarbon clusters also exhibit radial velocity distributions which vary systematically with chemical composition, as already pointed out for the fluorocarbon ions. The same is observed for structures of the type $\mathrm{C}_{n} \mathrm{H}_{m} X(X=\mathrm{F}$ or $\mathrm{O})$ present in the spectra of, e.g., PVDF (Ref. 11) or peptide targets, respectively. Pure hydrogen ions $\left(\mathrm{H}_{n}^{+}, n=1,2,3\right)$ show, in all investigated targets, an effect similar to the one described in Sec. III B above: the mean velocity and the width of the distributions decrease with increasing $n$. The results for NC targets are shown in Fig. 7. The values of the mean velocity and mean kinetic energy of hydrogen ions are higher than the values for the heavier ions.

It is worth noting the behavior observed for ions such as $\mathrm{Na}^{+}, \mathrm{NO}_{2}^{+}$, and the immonium ions ejected from the peptide targets (Table III). $\mathrm{NH}_{4}^{+}, \mathrm{NO}_{2}^{+}$, and $\mathrm{Na}^{+}$have always high and negative $\left\langle v_{x}\right\rangle$ (we note that $\left\langle v_{x}\right\rangle$ is close to zero for $\mathrm{Na}^{+}$ ejected from the polymer targets). The latter ions may be linked to the ejection of large precursors which have negative $\left\langle v_{x}\right\rangle$. One possibility is that these low-mass ions are formed by fragmentation from highly excited species (e.g., macroradicals, molecular ion complexes) immediately after ejection. The same explanation may apply to the immonium ions as well. These ions have always $\left\langle v_{x}\right\rangle$ with the same sign and similar or higher magnitude than the molecular ions (Table III). The "mass defect" (i.e., longer flight times than expected, see Sec. III A) observed for the immonium ions supports this hypothesis.

The velocity distributions of hydrocarbon ions ejected from $\mathrm{C}_{60}$ thin films have also been measured. In this particular case only carbon atoms are present in the molecular structure of the targets. Therefore, the observed $\mathrm{C}_{n} \mathrm{H}_{m}^{+}$are derived most probably from surface contaminants, although some bulk contamination during the film growth cannot be completely ruled out. Contrary to all other compounds investigated, it has been observed that $\left\langle v_{x}\right\rangle \approx 0$ for most of the sec- 
TABLE III. Results from the radial velocity distribution of several low-mass ions and immonium ions (fingerprint ions characteristic of the peptide's constituent aminoacids) ejected from various targets. Primary ions: 72.3 - and 78-MeV ${ }^{127} \mathrm{I}$.

\begin{tabular}{lrrr}
\hline \hline & & \multicolumn{2}{c}{$\left\langle v_{x}\right\rangle(\mathrm{m} / \mathrm{s})^{\mathrm{a}}$} \\
Ion & \multicolumn{1}{c}{ LHRH } & \multicolumn{1}{c}{ Substance P } & \multicolumn{1}{c}{$\mathrm{NC}$} \\
\hline $\mathrm{NH}_{4}^{+}$ & $-2400 \pm 500$ & $-580 \pm 350$ & $0 \pm 300$ \\
$\mathrm{H}_{3} \mathrm{O}^{+}$ & $3300 \pm 700$ & $-60 \pm 350$ & $185 \pm 280$ \\
$\mathrm{Na}^{+}$ & $-1600 \pm 500$ & $-900 \pm 350$ & $60 \pm 260$ \\
$\mathrm{NO}^{+}$ & & $75 \pm 300$ & $370 \pm 270$ \\
$\mathrm{NO}_{2}^{+}$ & & $-1120 \pm 250$ & $-730 \pm 160$ \\
$\mathrm{Immonium}^{+}$ & & & \\
$\mathrm{CH}_{4} \mathrm{~N}^{+}$ & $-2000 \pm 400$ & $-600 \pm 200$ & \\
$\mathrm{C}_{2} \mathrm{H}_{6} \mathrm{NO}^{+}$ & $-2200 \pm 300$ & & \\
$\mathrm{C}_{4} \mathrm{H}_{8} \mathrm{~N}^{+}$ & $-2000 \pm 230$ & $-540 \pm 200$ & \\
$\mathrm{C}_{5} \mathrm{H}_{12} \mathrm{~N}^{+}$ & $-2100 \pm 230$ & & \\
$\mathrm{C}_{5} \mathrm{H}_{8} \mathrm{~N}_{3}^{+}$ & $-1600 \pm 200$ & & \\
$\mathrm{C}_{8} \mathrm{H}_{10} \mathrm{~N}^{+}$ & & $-400 \pm 200$ & \\
$\mathrm{C}_{8} \mathrm{H}_{10} \mathrm{NO}^{+}$ & $-1600 \pm 200$ & & \\
$\mathrm{C}_{10} \mathrm{H}_{11} \mathrm{~N}_{2}^{+}$ & $-1650 \pm 180$ & \\
{$\left[M+\mathrm{H}^{+} \mathrm{b}\right.$} & $-900 \pm 60$ & $-580 \pm 90$ & \\
\hline \hline
\end{tabular}

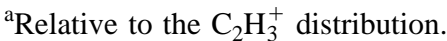

${ }^{\mathrm{b}}[M+\mathrm{H}]^{+}$is the protonated molecular ion.

ondary ions up to masses $\approx 100 \mathrm{u}$. However, the dependence of the $\left\langle v_{x}^{2}\right\rangle$ on the degree of hydrogenation can still be clearly distinguished (Fig. 8). The explanation of such behavior is not clear at present. It may be coupled to the facts that hydrocarbon ions originate mainly from adsorbed contaminants and/or that the ejection mechanisms from a $\mathrm{C}_{60}$ matrix are distinct from the polymeric and biomolecular targets. We note that intact $\mathrm{C}_{60}$ molecular ions are ejected preferentially normal to the surface $\left(\left\langle v_{x}\right\rangle \approx 0\right)$, while an asymmetric $v_{x}$ distribution relative to the normal is observed for intact biomolecules $\left(\left\langle v_{x}\right\rangle\right.$ is negative) ${ }^{16-18}$ This may indicate

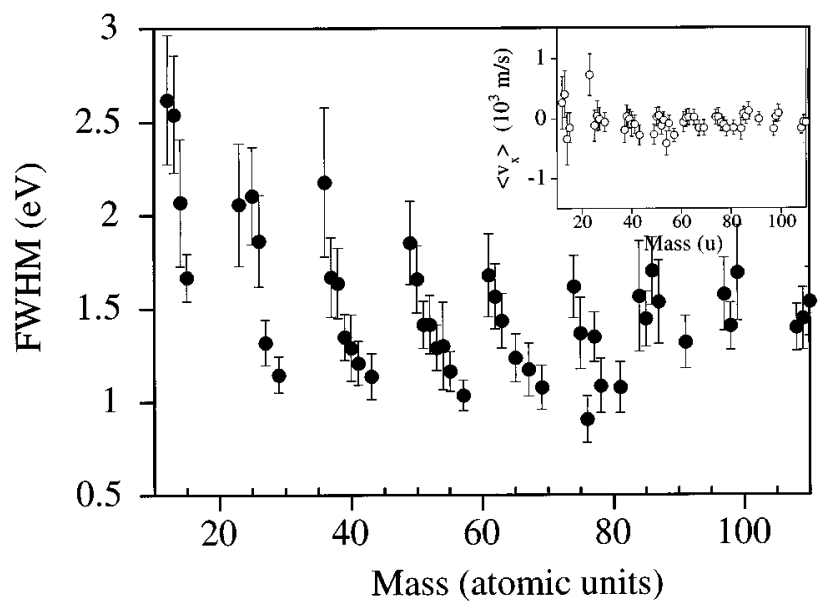

FIG. 8. Full width at half maximum (FWHM) of the radial velocity distributions ( $x$ component) from hydrocarbon ions ejected from $\mathrm{C}_{60}$ targets vs secondary ion mass. The projectiles were 72.3$\mathrm{MeV}{ }^{127} \mathrm{I}^{13+}$ ions. The inset shows the results obtained for the mean velocity $\left\langle v_{x}\right\rangle$ for the same ions.

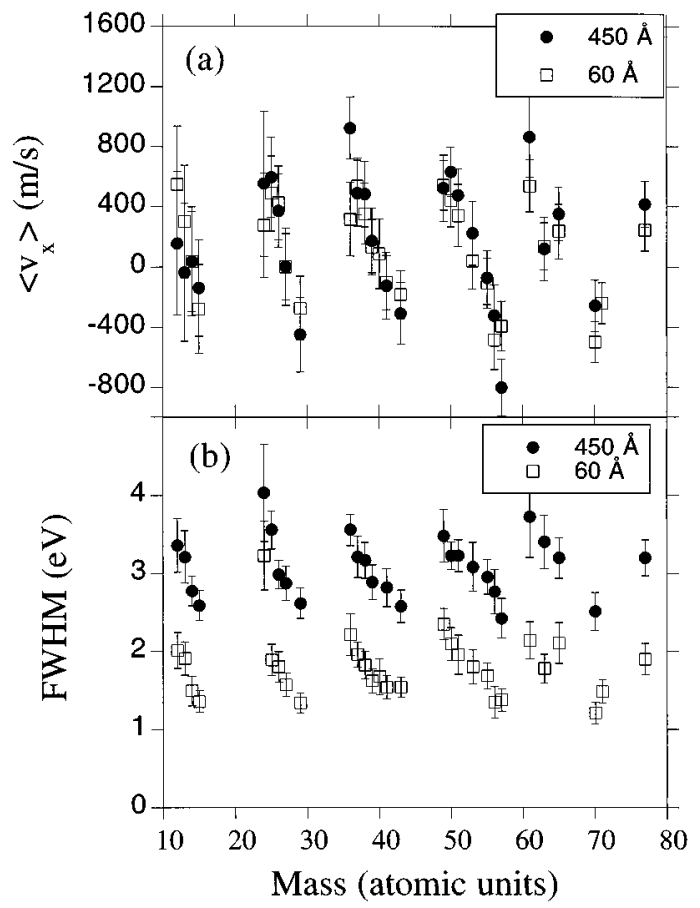

FIG. 9. (a) Mean velocities $\left\langle v_{x}\right\rangle$ and (b) FWHM $\left(=0.5 m\left[\left\langle v_{x}^{2}\right\rangle-\left\langle v_{x}\right\rangle^{2}\right]\right)$ of the $x$ velocity distributions of hydrocarbon secondary ions ejected from NC films with $60 \AA(\square)$ and $450 \AA$ (-) as a function of ion mass. $72.3-\mathrm{MeV}{ }^{127} \mathrm{I}^{13+}$ were used as projectiles.

that the hydrodynamic type of ejection is not efficient in $\mathrm{C}_{60}$, and an evaporative type of ejection dominates. ${ }^{10}$

\section{E. Thickness dependence}

As already stated, ions sputtered from thicker targets show typically broader velocity distributions. For example, ejecta from LHRH and PTFE targets, which are the thickest employed in this work $(\approx 5 \mu \mathrm{m})$, had the broadest velocity distributions of all tested targets (Table II). It is not the goal of this work to perform a systematic investigation of thickness effects on the velocity distributions. This has been done in detail by Fenyö et al. ${ }^{34}$ and Wien et al. ${ }^{12}$ for $\mathrm{H}_{n}^{+}$ions. Here, measurements are reported only for the $v_{x}$ velocity component for secondary ions ejected from $N C(60 \AA$ and $450 \AA$ thick) and PS targets (100 $\AA, 3000 \AA$, and $>1 \mu \mathrm{m}$ thick). The observed results can be summarized as follows: (i) ions sputtered from thicker targets have broader $v_{x}$ distributions, which is valid even for relatively "heavy" ions ( $m / z$ up to $\approx 150 \mathrm{u}$ ); (ii) the broadening, however, is enhanced for lighter ions (up to $\mathrm{m} / \mathrm{z}$ around 25); (iii) the relative difference of the FWHM or $\left\langle v_{x}\right\rangle$ values among ions in the same $\mathrm{C}_{n} \mathrm{H}_{m}$ series, i.e., the dispersion in these quantities, is weakly affected by the target thickness (Fig. 9), except, again, for the very light ions; (iv) the width of the velocity distribution of $\mathrm{H}^{-}$decreases for thicker samples, but increases for more massive negative ions. The novelty here, compared to previously published data, is that broadening of the distributions is observed for all investigated ions (up to $m / z \approx 150$ ) and not only for hydrogen ions. ${ }^{12,27,34,35}$ 
The increase in the width of the velocity distributions with thickness, at least for $\mathrm{H}_{n}^{+}$ions, has been attributed by various authors to the residual track potential at the time of ejection. ${ }^{12,27,34}$ It was demonstrated that the deposited energy transiently stored as potential (Coulomb) energy may add to the $\mathrm{H}_{n}^{+}$ions mean velocities and mean-square velocities to an extent which depends on the neutralization time (assumed to be thickness dependent). It is an open question whether this explanation is also applicable to more massive species. If so, it is unclear whether it is effected directly by electrostatic repulsion from the transiently charged track, and/or by a more efficient coupling (conversion) of the potential energy into atomic motion (kinetic energy) for thicker samples with longer neutralization times. In both cases, rapid neutralization is causing less energy to be transferred to the ejected molecules. Therefore, the thickness dependence of $\left\langle v_{x}^{2}\right\rangle$ may be generally coupled to the energy density in the track. The track either cools faster in thin samples or rapid neutralization leads to "colder" track (due to less efficient conversion of electronic energy into atomic motion), resulting in narrower velocity distributions. Other factors such as the straggling in the secondary-ion velocity via gas-phase collisions, ${ }^{32,36}$ or the effect of a nonflat surface composed of segments with different orientation can also be considered as source of smoothing and broadening of the radial velocity distributions. Further investigations in samples with wellcontrolled topography and thickness are necessary to evaluate the relative importance of all different factors.

\section{F. $d E / d x$ dependence}

Experiments on the dependence of the radial velocity distributions on the primary ion stopping power were performed only for the peptides SP and LHRH. The general trend is that the $\left\langle v_{x}\right\rangle$ for all investigated ions, including the molecular ion peak, become closer to zero for decreasing $d E / d x$. In other words, the amplitude of variation of the $\left\langle v_{x}\right\rangle$ and FWHM, in each $\mathrm{C}_{n} \mathrm{H}_{m}^{+}$series with fixed $n$, decreases for lower stopping powers. This is illustrated in Fig. 10, where the $\left\langle v_{x}\right\rangle$ and FWHM obtained for hydrocarbon ions ejected from a LHRH target impacted by $78.2-\mathrm{MeV}^{12} \mathrm{I}$ and $9.9-\mathrm{MeV}{ }^{16} \mathrm{O}$ ions are shown. [Note that this result is different from the effect of thickness which produces a shift of the moments without changing their amplitude of variation, Fig. 9(b).] The $\left\langle v_{x}\right\rangle$ of several ions ejected from LHRH and SP is plotted against $d E / d x$ in Fig. 11. It is seen that the magnitude of the mean velocities decreases roughly linearly with decreasing stopping power for both ions with positive (e.g., $\mathrm{C}_{3} \mathrm{H}^{+}, \mathrm{C}_{4} \mathrm{H}_{3}^{+}$) or negative (e.g., $\mathrm{NH}_{4}^{+}, \mathrm{NO}_{2}^{+}$) mean velocities.

This decrease in the dispersion of $\left\langle v_{x}\right\rangle$ and FWHM for lower stopping powers appears to be linked to a "weaker" impulse imparted to the ejecta (either radially or axially to the track) and to a lower local energy density. The momentum imparted to the molecules $\mathbf{p}$, in the pressure pulse formalism is proportional to $(d E / d x)_{\mathrm{eff}}$ [see Eq. (B7) in Ref. $32]$, where $(d E / d x)_{\text {eff }}$ is the fraction of $d E / d x$ going into expansion. This is in qualitative agreement with our data. Most of the ions have zero-velocity intercept when extrapolated from linear fits of the experimental points for $d E /$ $d x \rightarrow 0$ (Fig. 11). However, $\mathrm{NO}_{2}^{+}$and $\mathrm{C}_{10} \mathrm{H}_{11} \mathrm{~N}_{2}^{+}$ejected from SP targets have clearly nonzero intercepts which may be indicative of different route for their formation (e.g., gas-phase
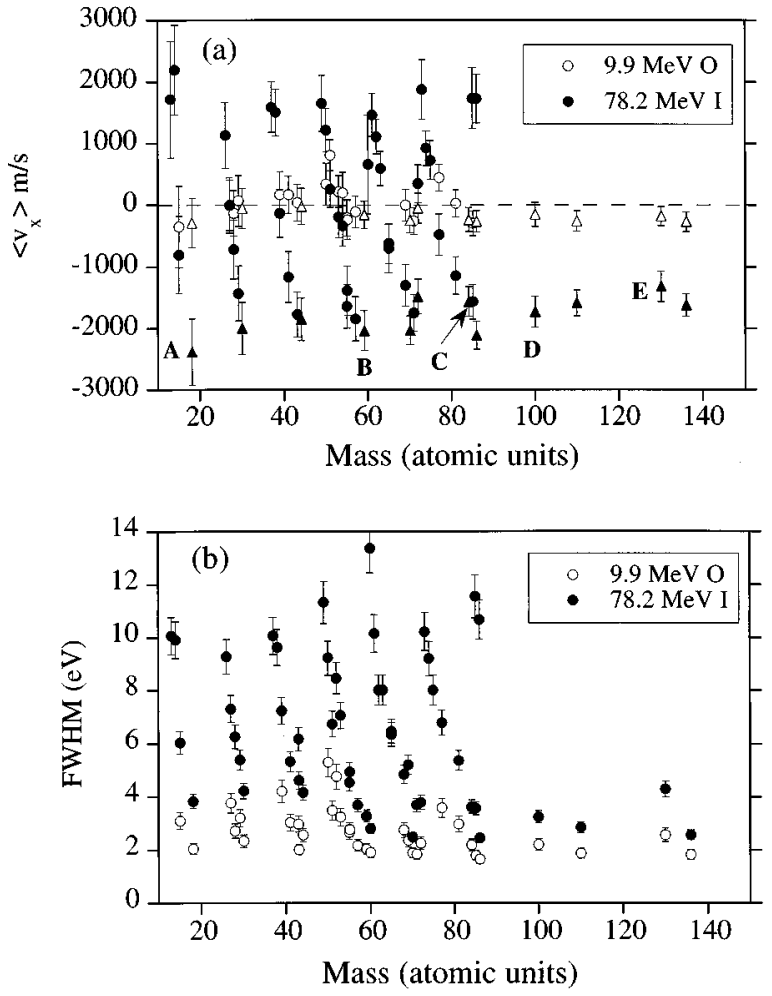

FIG. 10. Moments of the velocity distributions ( $x$ component) of secondary ions ejected from a LHRH target by $9.9-\mathrm{MeV}{ }^{16} \mathrm{O}$ ions (open symbols, $d E / d x \approx 112 \mathrm{eV} / \AA$ ) and $78.2-\mathrm{MeV}^{127} \mathrm{I}$ ions (closed symbols, $d E / d x \approx 655 \mathrm{eV} / \AA$. The mean velocities are displayed in (a) and the FWHM $\left(\propto\left\langle v_{x}^{2}\right\rangle\right)$ in (b). In (a) the triangles are used to indicate secondary ions different from hydrocarbons. Particular ions are indicated by capital letters: $A=\mathrm{NH}_{4}^{+}, \quad B=\mathrm{C}_{3} \mathrm{H}_{7} \mathrm{O}^{+}$, $C=\mathrm{C}_{5} \mathrm{H}_{10} \mathrm{~N}^{+}$or $\mathrm{C}_{8} \mathrm{H}_{8} \mathrm{O}^{+}, D=\mathrm{C}_{6} \mathrm{H}_{12} \mathrm{O}^{+}$or $\mathrm{C}_{6} \mathrm{H}_{14} \mathrm{~N}^{+}, E=\mathrm{C}_{9} \mathrm{H}_{8} \mathrm{~N}^{+}$.

dissociation of sputtered molecular ions). We point out that while zero mean radial velocity for most ions may have a clear physical meaning (at $d E / d x=0$ ions cannot be sputtered so their velocity will be obviously zero) the real picture is probably more complicated than that. The validity of a particular model of electronic sputtering operative at higher $d E / d x$ has still to be proven at lower $d E / d x$. For instance, at low $d E / d x$, close to the threshold for ion ejection, the pressure pulse model may not be applicable ${ }^{37}$ (instead a statistical model may better describe the ejection process).

It is seen that the dependence of $\left\langle v_{x}\right\rangle$ on the primary ion stopping power is stronger for ions emitted from LHRH. This may be coupled to the target-thickness effects as discussed above. The longer track neutralization time in LHRH may result in a more effective conversion of the initial potential energy into expansion energy (molecular motion) and a higher $\left\langle p_{x}\right\rangle$ being imparted to the ejected ions.

\section{CONCLUSIONS}

The $v_{x}$ and $v_{y}$ components of the initial radial velocity distributions of low mass (up to $m / z \approx 300 \mathrm{u}$ ) secondary ions, sputtered by $\mathrm{MeV}$ atomic ions from molecular solids (polymers, bioorganic molecules, and fullerene targets) have been determined. The first $(\langle v\rangle)$ and second $\left(\left\langle v^{2}\right\rangle\right)$ moments of the 


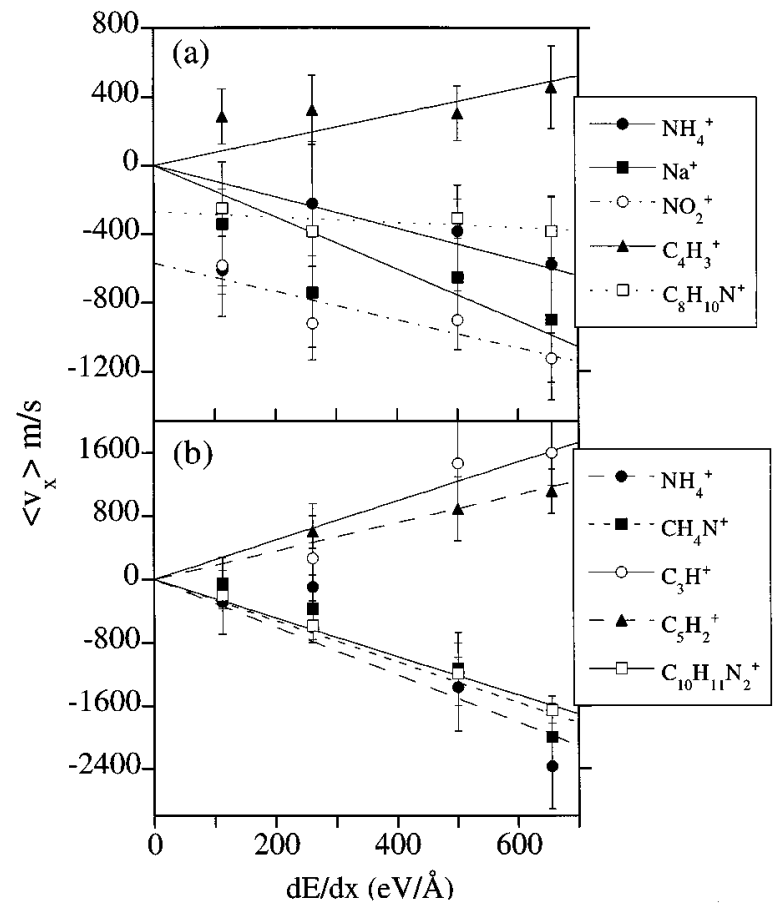

FIG. 11. Mean radial velocities ( $x$ component) of several secondary ions ejected from (a) substance-P and (b) LHRH targets as a function of the primary ion stopping power, $d E / d x$. The solid and dashed lines are linear fits to the experimental points.

velocity distributions of positive ions are seen to vary systematically with the degree of hydrogenation-fluorination of secondary ions of the type $\mathrm{C}_{n} \mathrm{H}_{m}, \mathrm{C}_{n} \mathrm{~F}_{m}, \mathrm{C}_{n} \mathrm{H}_{m} \mathrm{~F}$, and $\mathrm{C}_{n} \mathrm{H}_{m} \mathrm{O}$. Such effects decrease at lower primary ion stopping power and are not observed for negative ions. For the lowest stopping power the values of the mean radial velocity approach zero for all secondary ions, independent of their chemical composition. This phenomenon, detected in different types of molecular solids, is found to be general feature in the fast-ion-induced sputtering of dielectric solids. However, the magnitudes of $\langle v\rangle$ and $\left\langle v^{2}\right\rangle$ and their variation with atomic composition depend on sample specific factors such as the target chemical structure and thickness, which influence the time scale of energy dissipation in the ion tracks.

The direction of the momentum transferred to the target molecules, and thus the $\left\langle v_{x}\right\rangle$ and $\left\langle v_{y}\right\rangle$ gained by the emitted ions is coupled to the geometry of the $\mathrm{MeV}$ ion impact and to the specific ejection mechanism operating. The impulse transferred either radially or axially relative to the track core results in velocity distributions symmetric around the normal for the $y$ component (independent of the ejection mechanism invoked) but asymmetric distributions for the $v_{x}$ component of the radial velocity. This is most probably the reason for observing $\left\langle v_{y}\right\rangle \approx 0$ for all secondary ions, and a "chemical composition" "dependent $\left\langle v_{x}\right\rangle$.

The chemical transformations necessary for ion formation and the processes leading to ejection are both a function of the amount and the gradient of the deposited energy at a particular point from the track center. This interconnection results in the regular dependence of the properties of ejected species (e.g., mean exit velocity) on their chemical composition. In other words, the correlation between the ejection dynamics and the ion chemical composition reflects the fastion track structure and the impact geometry. It results from the spatial inhomogeneity of the energy deposition events in the track and the existence of different locations where particular ions are formed relative to the point of impact.

The observed effects demonstrate that the ionic component of the electronically sputtered material carries important information on ion-solid interactions and specifically on the structure of the $\mathrm{MeV}$ ion track. They also permit one to qualitatively compare the characteristics of an ion track (e.g., how fast the deposited energy is quenched) and/or the dynamics of ion ejection in specific materials.

\section{ACKNOWLEDGMENTS}

This work was supported by the Swedish Natural Sciences Research Council (NFR), the Angstrom and Cluster Consortia and the National Research Council of Brazil $(\mathrm{CNPq})$. We are grateful to G. Brinkmalm, D. Fenyö, and H. F. Kammer for their contributions to the results discussed in this paper, and to I. Bitensky and R. E. Johnson for helpful discussions.
*Corresponding author, permanent address: Instituto de Física, Universidade Federal do Rio Grande do Sul, 91501-970 Porto Alegre, RS, Brazil.

${ }^{1}$ R. L. Fleischer, P. Price, and R. M. Walker, Nuclear Tracks in Solids (University of California Press, Berkeley, 1975).

${ }^{2}$ M. Toulemonde, S. Bouffard, and F. Studer, Nucl. Instrum. Methods Phys. Res. B 91, 108 (1994).

${ }^{3}$ R. E. Johnson, Int. J. Mass Spectrom. Ion Proc. 78, 357 (1987).

${ }^{4}$ J. L. Magee, and A. Chatterjee, in Kinetics of Nonhomogeneous Processes, edited by G. Freeman (Wiley, New York, 1987), p. 171.

${ }^{5}$ K. Wien, Rad. Eff. Def. Solids 109, 137 (1989); Nucl. Instrum. Methods Phys. Res. B 65, 149 (1992).

${ }^{6}$ B. Sundqvist and R. D. Macfarlane, Mass Spec. Rev. 4, 421 (1985); P. Demirev, Mass Spec. Rev. (to be published).

${ }^{7}$ R. D. Macfarlane and D. F. Torgerson, Phys. Rev. Lett. 36, 486 (1976).

${ }^{8}$ T. A. Tombrello, Int. J. Mass Spectrom. Ion Proc. 126, 11 (1993).
${ }^{9}$ W. Ens, B. U. R. Sundqvist, P. Håkansson, A. Hedin, and G. Jonsson, Phys. Rev. B 39, 763 (1989).

${ }^{10}$ G. Brinkmalm, P. Demirev, D. Fenyö, P. Håkansson, J. Kopniczky, and B. U. R. Sundqvist, Phys. Rev. B 47, 7560 (1993).

${ }^{11}$ R. M. Papaléo, G. Brinkmalm, D. Fenyö, J. Eriksson, H.-F. Kammer, P. Demirev, P. Håkansson, and B. U. R. Sundqvist, Nucl. Instrum. Methods Phys. Res. B 91, 667 (1994).

${ }^{12}$ K. Wien, C. Koch, and N. vanTan, Nucl. Instrum. Methods Phys. Res. B 100, 322 (1995).

${ }^{13}$ R. R. Lucchese, J. Chem. Phys. 86, 443 (1987).

${ }^{14}$ R. E. Johnson, B. U. R. Sundqvist, A. Hedin, and D. Fenyö, Phys. Rev. B 40, 49 (1989).

${ }^{15}$ I. Bitensky and E. S. Parilis, Nucl. Instrum. Methods Phys. Res. B 21, 26 (1987).

${ }^{16}$ R. Moshammer, R. Matthäus, K. Wien, and G. Bolbach, in 5th International Conference on Ion Formation from Organic Solids (IFOSV), Lövanger, Sweden, 1989, edited by A. Hedin, 
B. U. R. Sundqvist, and A. Benninghoven (Wiley, Chichester, 1990), p. 17.

${ }^{17}$ W. Ens, B. U. R. Sundqvist, P. Håkansson, D. Fenyö, A. Hedin, and G. Johnson, J. Phys. (Paris) Colloq. 50, C2-9 (1989).

${ }^{18}$ D. Fenyö, A. Hedin, P. Håkansson, and B. U. R. Sundqvist, Int. J. Mass Spectrom. Ion Proc. 100, 63 (1990).

${ }^{19}$ R. M. Papaléo, P. Demirev, J. Eriksson, P. Håkansson and B. U. R. Sundqvist, Nucl. Instrum. Methods Phys. Res. B 107, 308 (1996).

${ }^{20}$ G. Säve, P. Håkansson, B. U. R. Sundqvist, U. Jönsson, G. Olofsson, and M. Malmquist, Anal. Chem. 59, 2059 (1987).

${ }^{21}$ G. Brinkmalm, P. Håkansson, J. Kjellberg, P. Demirev, B. U. R. Sundqvist, and W. Ens, Int. J. Mass Spectrom. Ion Proc. 114, 183 (1992).

${ }^{22}$ H. Danigel and R. D. Macfarlane, Int. J. Mass Spectrom. Ion Proc. 39, 157 (1981).

${ }^{23}$ R. M. Papaléo et al. (unpublished).

${ }^{24}$ P. Demirev, G. Brinkmalm, D. Fenyö, P. Håkansson, and B. U. R. Sundqvist, Int. J. Mass Spectrom. Ion Proc. 111, 41 (1991).

${ }^{25}$ R. Moshammer, Ph.D. thesis, Institute of Nuclear Physics, Technische Hochschule Darmstadt, Germany, 1991.

${ }^{26}$ R. D. Macfarlane, J. C. Hill, and D. L. Jacobs, J. Trace Microprobe Tech. 4, 281 (1986).
${ }^{27}$ R. D. Macfarlane and D. L. Jacobs, in 4th International Conference on Ion Formation from Organic Solids (IFOS IV), Münster, 1987, edited by A. Benninghoven (Wiley, Chichester, 1989), p. 71

${ }^{28}$ G. Betz and K. Wien, Int. J. Mass Spectrom. Ion Proc. 140, 1 (1994).

${ }^{29}$ O. Becker and K. Wien, Nucl. Instrum. Methods Phys. Res. B 16, 456 (1986).

${ }^{30}$ M. A. Park, E. A. Schweikert, and E. F. D. Silveira, J. Chem. Phys. 96, 3206 (1992).

${ }^{31}$ B. U. R. Sundqvist, Int. J. Mass Spectrom. Ion Proc. 126, 1 (1993).

${ }^{32}$ D. Fenyö and R. E. Johnson, Phys. Rev. B 46, 5090 (1992).

${ }^{33}$ E. S. Parilis, L. M. Kishinevsky, N. Y. Turaev, B. E. Baklitzky, F. F. Umarov, V. K. Verliger, and I. S. Bitensky, Atomic Collisions on Solid Surfaces (North-Holland, Amsterdam, 1993).

${ }^{34}$ D. Fenyö, P. Håkansson, and B. U. R. Sundqvist, Nucl. Instrum. Methods Phys. Res. B 84, 31 (1994).

${ }^{35}$ S. Widdiyasekera, P. Håkansson, and B. U. R. Sundqvist, Nucl. Instrum. Methods Phys. Res. B 33, 836 (1988).

${ }^{36}$ I. Bitensky (unpublished).

${ }^{37}$ D. Fenyö, Phys. Rev. B 47, 8263 (1993). 